\title{
Hepatitis $C$ infection substantially reduces survival of alcohol-dependent patients
}

This article was published in the following Dove Press journal:

Clinical Epidemiology

\section{Roberto Muga' \\ Arantza Sanvisens' \\ Inmaculada Jarrin ${ }^{2}$ \\ Daniel Fuster' \\ Ferran Bolao 3 \\ Jordi Tor' \\ Alvaro Muñoz ${ }^{4}$}

'Department of Internal Medicine, Hospital Universitari Germans Trias i Pujol, Universitat Autònoma de Barcelona, Badalona, Spain; ${ }^{2}$ National Center of Epidemiology, Institute of Health Carlos III, Madrid, Spain; ${ }^{3}$ Department of Internal Medicine, Hospital Universitari de BellvitgeIDIBELL, Universitat de Barcelona, L'Hospitalet de Llobregat, Spain; ${ }^{4}$ Department of Epidemiology, Johns Hopkins University, Bloomberg School of Public Health, Baltimore, MD, USA

Correspondence: Roberto Muga Department of Internal Medicine, Hospital Universitari Germans Trias i Pujol, Universitat Autònoma de Barcelona, Ctra. canyet s/n, 08916 Badalona, Spain

Tel +34 934651200 ext3582

Email rmuga.germanstrias@gencat.cat
Background: Heavy alcohol use is associated with life-threatening complications including progressive liver disease. We aimed to analyze the impact of hepatitis $\mathrm{C}$ virus (HCV) infection on survival and liver-related death in alcohol-dependent patients.

Patients and methods: This is a longitudinal study in patients seeking treatment of alcohol abuse between 2000 and 2010. Information on alcohol use characteristics, alcoholic liver disease, and HCV infection were obtained at entry. Cumulated mortality and causes of death were ascertained through clinical records and death registry.

Results: A total of 819 patients ( $81.6 \%$ men) underwent ethanol detoxification; age was 44 (interquartile range [IQR] 38-51) years; the duration of heavy alcohol use was 14 (IQR 6-24) years; and the alcohol consumption was 190 (IQR 120-250) g/day. The prevalence of HCV infection was $15.8 \%$. There were 129 (16.9\%) deaths during 5,117 persons-year (p-y) of follow-up (median follow-up 6.4 [IQR 4.3-9.2] years); 31 (24.6\%) deaths were observed among the HCV-positive patients, and 98 (15.4\%) deaths were observed among the HCV-negative patients. The mortality rate was significantly $(P=0.03)$ higher among the HCV-positive patients $(3.84 \times 100 \mathrm{p}-\mathrm{y} ; 95 \%$ confidence interval $[\mathrm{CI}]: 2.70,5.46)$ than among the HCV-negative patients $(2.27 \times 100 \mathrm{p}-\mathrm{y} ; 95 \%$ CI: $1.86,2.77$ ). Survival times for the HCV infected patients were $34 \%$ shorter (time ratio relative to HCV negative: 0.66 ; $95 \%$ CI: $0.51,0.86$ ). The main causes of death in the HCV-positive and -negative patients were liver-related mortality (48.4\%) and neoplasia (22.4\%), respectively. The liver-related mortality was significantly higher among the HCV-positive patients (adjusted sub-distribution hazard ratio [asHR] 3.65; 95\% CI: $1.72,7.78 ; P=0.001)$.

Conclusion: HCV infection compromises the survival of patients with alcohol abuse/dependence. The new direct antiviral agents for the treatment of HCV infection may result in better clinical outcomes.

Keywords: hepatitis C virus, alcohol use disorder, survival, liver disease, mortality

\section{Introduction}

Harmful alcohol use is one of the leading causes of preventable death in Western countries, with excessive alcohol consumption as the third leading cause of premature death behind smoking and obesity. Mortality among individuals with heavy alcohol use is high due to several life-threatening complications related to excessive alcohol consumption, including progressive liver disease, cancer, nonnatural causes, and cardiovascular disease.

Among individuals with excessive alcohol consumption, 10-20\% develop alcoholic liver disease (ALD) in the course of chronic, heavy drinking and acute alcoholic hepatitis, the most florid manifestation of ALD will occur in some cases. ${ }^{1}$ ALD has 
been reported to affect $>2.5$ million people in the USA and is the second most frequent indication for liver transplant in the USA and western Europe. ${ }^{2}$ Liangpunsakul ${ }^{3}$ summarized nationwide data on the clinical characteristics of alcoholic hepatitis in the USA, indicating that $\sim 20 \%$ of patients have hepatitis $\mathrm{C}$ virus (HCV) infection and in-hospital mortality of episodes remains high. Furthermore, liver-related mortality increased globally from 2005 to 2015 and this trend largely reflects changes in major risk factors, such as excessive alcohol consumption and $\mathrm{HCV}$ infection. ${ }^{4}$

$\mathrm{HCV}$ infection affects $2-3 \%$ of the general population, disregarding marked regional differences. ${ }^{5}$ Mortality and disability-adjusted life-years due to $\mathrm{HCV}$ infection have increased, more than double since $1990 .{ }^{6} \mathrm{HCV}$ infection has been recognized as a main risk factor for the progression of liver disease (ie, cirrhosis and hepatocellular cancer) and liver-related deaths worldwide, with nearly a quarter of cirrhosis deaths being attributed to this infection. ${ }^{4}$

The impact of HCV infection in individuals with excessive alcohol consumption is relevant due to the fact that those who are infected are more likely to drink alcohol than someone without $\mathrm{HCV}^{7}$ Excessive alcohol consumption may explain much of the poor prognostic outcomes and liver-related deaths in patients with $\mathrm{HCV}$ infection. ${ }^{8-12}$ The fraction of cirrhosis of the liver attributable to excessive alcohol consumption in patients with HCV infection is estimated to be $36 \%{ }^{13}$ and the alcohol attributable risk for liver transplantation and liver-related death associated with heavy alcohol use is estimated to be 67 and $68 \%$, respectively. ${ }^{12}$

The molecular mechanisms underlying how alcohol exacerbates HCV infection and worsens liver injury remain to be elucidated. However, major components of the interactions between alcohol and HCV infection include the modulation of cytokine production, lipopolysaccharide-TLR4 signaling, and reactive oxygen species production. ${ }^{14,15}$

Hepatic oxidative stress and mitochondrial abnormalities are almost universally observed in patients with chronic $\mathrm{HCV}$ and appear to be an intrinsic component of the disease. ${ }^{14}$ There is in vivo evidence of increased oxidative stress as the mechanism of synergy between alcohol and HCV in advanced liver damage, as the risk of developing oxidative stress during chronic HCV infection, is increased by heavy alcohol consumption and associated with increased fibrosis of the liver. ${ }^{16,17}$

We analyzed the role of chronic HCV infection on baseline liver damage, long-term outcomes, and cause-specific mortality in a cohort of clinically well-characterized patients receiving treatment and care for alcohol dependence before the introduction of all-oral, direct acting antivirals (DAAs) for the treatment of $\mathrm{HCV}$ infection. In the context of changing the treatment paradigm of $\mathrm{HCV}$ infection, ${ }^{18}$ we theorize that the burden of liver disease in alcohol-dependent patients with $\mathrm{HCV}$ infection may result in an excess mortality that could be reduced in the era of new DAAs.

\section{Patients and methods \\ Study population}

This longitudinal study was carried out in a cohort of patients admitted for the treatment of alcohol dependence between January 2000 and December 2010 in the following two hospital units in metropolitan Barcelona, Spain: Hospital Universitari de Bellvitge in L'Hospitalet de Llobregat and Hospital Universitari Germans Trias i Pujol in Badalona. All patients provided written informed consent. The study was conducted in compliance with the ethical standards for medical research and principles of good clinical practice in accordance with the World Medical Association's Declaration of Helsinki, following Spanish Law 14/2007 on Biomedical Research. The study was approved by the Ethics Committees of the Hospital Universitari de Bellvitge and the Hospital Universitari Germans Trias i Pujol.

A flow chart of admission to the study is shown in Figure 1. After applying exclusion criteria, the study population included 819 patients.

\section{Clinical assessment}

Patients were referred to inpatient detoxification by primary care physicians and specialists in addiction medicine at community-based centers. All patients received the diagnosis of alcohol dependence according to the Diagnostic and Statistical Manual of Mental Disorders, 4th edition (DSMIV), ${ }^{19}$ and the main criteria for referrals included severity of alcohol dependence, medical comorbidity, and the risk of alcohol withdrawal, among others.

On the day of admission, patients underwent an interview that included questions on the history of alcohol consumption and the use of other substances. History of alcohol consumption included age when started drinking, duration of alcohol abuse, and quantity of alcohol consumption at admission. Alcohol consumption was quantified in grams per day (10 g $=1$ standard drink unit).

In all cases, blood samples were drawn the day after admission for liver function tests including aspartate aminotransferase (AST), alanine aminotransferase (ALT), gamma glutamyl transferase (GGT), alkaline phosphatase, and total bilirubin. 


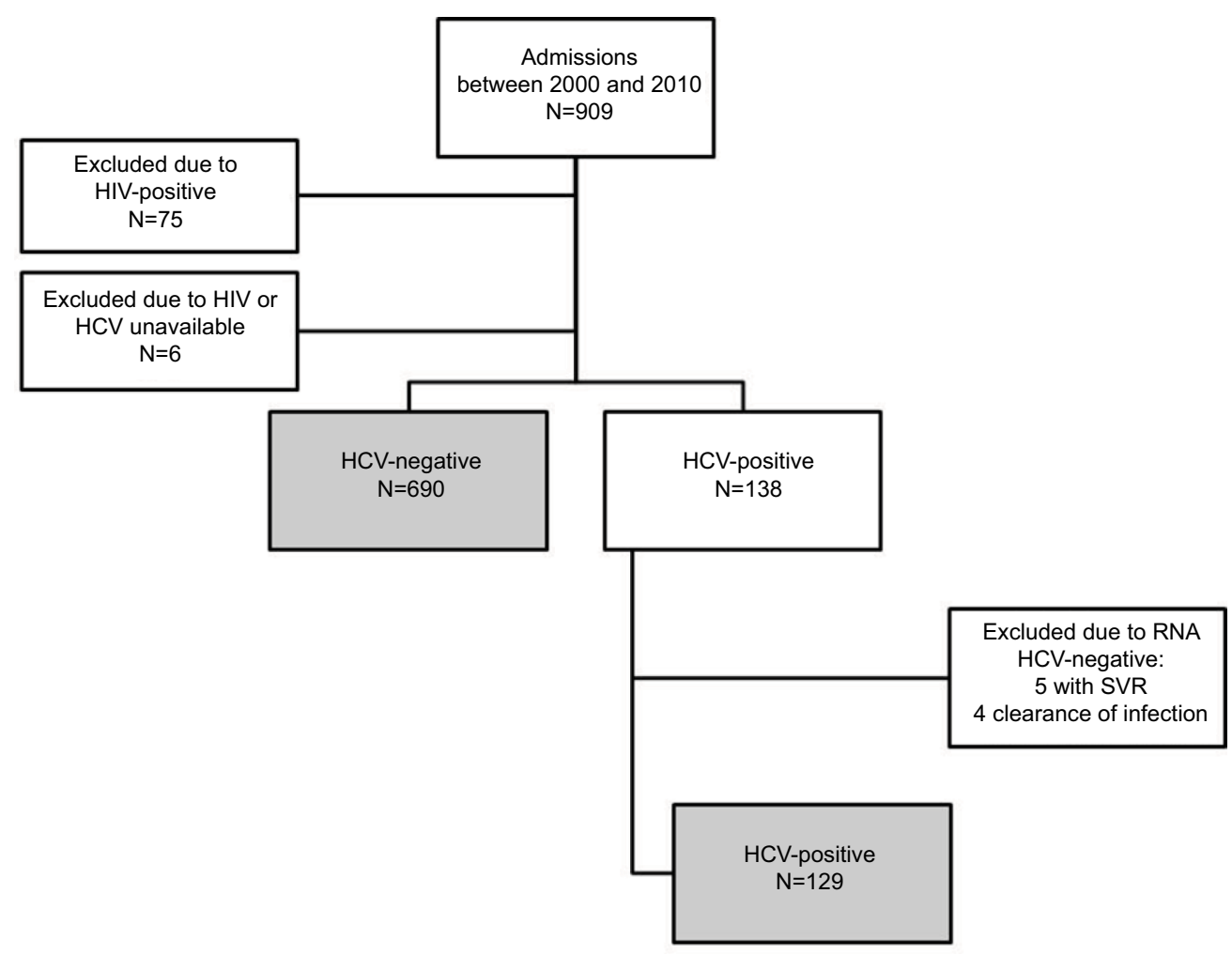

Figure I Selection of study population.

Abbreviations: HCV, hepatitis C virus; HIV, human immunodeficiency virus; SVR, sustained viral response.

Serum samples were tested for HCV and human immunodeficiency virus (HIV) infections. HCV screening was based on enzyme immunoassay (EIA) analysis and positive tests confirmed by real-time polymerase chain reaction (HCV RNA). Patients with a positive HCV RNA test were considered as having ongoing HCV infection. For the purposes of this study, patients with HIV infection were excluded.

ALD was diagnosed if patients met two or more of the following criteria: ${ }^{20,21}$ AST elevation 74-300 U/L, AST/ALT ratio $\geq 2$, and total bilirubin $>1.2 \mathrm{mg} / \mathrm{dL}$. Pharmacological treatment during admission included the administration of benzodiazepines, vitamin B complex, and other medications depending on medical comorbidity. On average, the length of stay was 6 days and, at discharge, patients were transferred to the primary care centers and recommended follow-up visits at an outpatient clinic.

\section{Mortality and causes of death}

Clinical outcomes and date and cause of death were ascertained through the review of clinical charts and crosschecking with the mortality register through June 30, 2014. Causes of death were coded according to the International Classification of Diseases Version 10 (ICD-10) ${ }^{22}$ and classified into the following five categories:
1. Liver related, including ALD, viral hepatitis, and hepatocellular carcinoma: B15-B19, C22, K65, K70-K77, and I85;

2. Cardiovascular: I00-I84 and I86-I99;

3. Malignant neoplasm, excluding hepatocellular carcinoma: C00-C21, C23-C97, D00-D09, and D37-D48;

4. Nonnatural (violence, accidents, and overdose): F10F19, V00-V99, W00-W99, X00-X99, and Y00-Y36; and

5. Others: codes not mentioned in prior causes.

\section{Statistical analyses}

Differences between the HCV-negative and the HCV-positive patients (ie, socio-demographics, alcohol use, liver function, and ALD) were assessed through the nonparametric MannWhitney test for continuous variables and the Chi-square test for categorical variables.

In all-cause mortality and liver-related mortality analyses, we used age as the time scale allowing the best possible control of a powerful predictor of mortality. We only considered person-time and events between the ages of 35 and 65 years, anchoring the time origin at age 35 years to prevent sparse events from having undue influence on results. We used late entry methods, left-truncating data at the time of entry 
and appropriately aligning person-time on the age scale, to accommodate individuals who entered the study after the age of 35 years. We administratively censored events and persontime after June 30, 2014. To quantify the putative reduction in survival times due to infection with $\mathrm{HCV}$, we fit conventional generalized gamma models whereby infection with $\mathrm{HCV}$ modified the location parameters. The antilog of the difference of the location parameters estimates the ratios of the percentiles of the HCV positive to those of HCV negative. ${ }^{23}$

For liver-related mortality, all unknown causes of death were assumed to be nonliver related, as most of them $(90.9 \%)$ were observed among the HCV-negative patients. We used the Kaplan-Meier method to estimate the cumulative incidence of death from any cause and Cox proportional hazards' models to calculate mortality hazard ratios (HRs). Proportional hazards' models on the sub-distribution hazard were used to estimate sub-distribution HRs (sHRs) for liver-related mortality, treating nonliver-related deaths as competing events. Multivariable models were adjusted for sex and ALD.

A set of sensitivity analyses was undertaken. Analyses were repeated using years from admission to treatment as the time scale, considering four different approaches to deal with unknown causes of death in liver-related mortality analyses (considering all unknown causes of death as another competing event, assuming all unknown causes of death to be liver related, assuming all unknown causes of death to be nonliver related, and imputing all unknown causes of death using multiple imputation by chained equations).

All statistical analyses were performed using the Stata software (Version 14.0; StataCorp LP., College Station, TX, USA).

\section{Results}

\section{Characteristics of the study population}

Eight hundred nineteen patients $(81.6 \%$ men) were included in the study. The median age at admission was 44 years (interquartile range [IQR] 38-51 years), the median duration of heavy alcohol use was 14 years (IQR 6-24 years), and the median alcohol consumption at admission was $190 \mathrm{~g} /$ day (IQR 120-250 g/day). A total of 129 (15.8\%) patients had HCV infection, and $14.2 \%$ of patients met the criteria for ALD.

Table 1 provides the baseline characteristics of patients according to HCV status at admission. Patients with $\mathrm{HCV}$

Table I Baseline characteristics of 819 patients admitted for the treatment of alcohol dependence and HCV status

\begin{tabular}{|c|c|c|c|}
\hline Variables & HCV negative ( $N=690), \mathrm{n}(\%)$ & HCV positive ( $N=129), n(\%)$ & $P$-value \\
\hline Men & $559(81.0)$ & $109(84.5)$ & 0.35 \\
\hline Age (years), median (IQR) & $45(38-52)$ & $42(38-46)$ & 0.001 \\
\hline \multicolumn{4}{|l|}{ Alcohol and substance use } \\
\hline Duration of alcohol dependence (years), median (IQR) & $10(4.1-20)$ & $10(4.5-21.5)$ & 0.88 \\
\hline Alcohol consumption (g/day), median (IQR) & $190(120-250)$ & $200(140-300)$ & 0.15 \\
\hline Cocaine consumption & & & 0.08 \\
\hline No & $537(77.8)$ & $96(74.4)$ & \\
\hline Yes & $51(7.4)$ & $17(13.2)$ & \\
\hline Unknown & $102(14.8)$ & $16(12.4)$ & \\
\hline \multicolumn{4}{|l|}{ Liver-related parameters, median (IQR) } \\
\hline $\operatorname{ALT}(U / L)(n=796)$ & $33(20-55.2)$ & $57.6(32.4-90.6)$ & $<0.001$ \\
\hline AST (U/L) $(n=796)$ & $36(22.2-70.2)$ & $59.4(33.6-96)$ & $<0.001$ \\
\hline GGT (U/L) (n=79I) & $108.6(45.6-280)$ & $162.6(85.8-323.4)$ & 0.003 \\
\hline Alkaline phosphatase $(U / L)(n=765)$ & $73(60-94.2)$ & $72(58.5-96)$ & 0.59 \\
\hline Bilirubin $(\mathrm{mg} / \mathrm{dL})(\mathrm{n}=794)$ & $0.7(0.5-1.1)$ & $0.7(0.5-1.2)$ & 0.13 \\
\hline Alcoholic liver disease & & & 0.22 \\
\hline No & $573(83.0)$ & $99(76.7)$ & \\
\hline Yes & $89(12.9)$ & $22(17.1)$ & \\
\hline Unknown & $28(4 . I)$ & $8(6.2)$ & \\
\hline \multicolumn{4}{|l|}{ Hematology and biochemistry, median (IQR) } \\
\hline Leukocytes $\left(\times 10^{9} / L\right)(n=805)$ & $6.7(5.5-8.3)$ & $6.4(5.1-8.0)$ & 0.10 \\
\hline Hemoglobin $(g / d L)(n=805)$ & $14.1(13-15.1)$ & $13.8(13-15.2)$ & 0.43 \\
\hline Platelets $\left(\times 10^{9} / \mathrm{L}\right)(\mathrm{n}=805)$ & $199(153-25 I)$ & $183(|23-24|)$ & 0.02 \\
\hline Creatinine $(\mathrm{mg} / \mathrm{dL})(\mathrm{n}=800)$ & $0.8(0.7-0.9)$ & $0.8(0.7-0.9)$ & 0.63 \\
\hline Glucose $(\mathrm{mg} / \mathrm{dL})(\mathrm{n}=79 \mathrm{l})$ & $93.7(86.5-104.5)$ & $92(83-100.9)$ & 0.04 \\
\hline Albumin $(g / L)(n=794)$ & $40(37-42)$ & $39(36-4 I)$ & 0.02 \\
\hline Total cholesterol $(\mathrm{mg} / \mathrm{dL})(\mathrm{n}=797)$ & $191.4(164.0-225.1)$ & 164.1 (139.6-189.5) & $<0.001$ \\
\hline Triglycerides $(\mathrm{mg} / \mathrm{dL})(\mathrm{n}=769)$ & $106.3(79-159.4)$ & $88.6(70-124.0)$ & $<0.001$ \\
\hline
\end{tabular}

Abbreviations: AST, aspartate aminotransferase; ALT, alanine aminotransferase, GGT, gamma glutamyl transferase; HCV, hepatitis C virus; IQR, interquartile range. 
infection were more likely to be younger and current cocaine users than HCV-negative patients. Platelet count, total serum cholesterol, triglycerides, glucose, and albumin levels were significantly different between the HCV-positive and -negative patients. Regarding liver function tests, serum levels of AST, ALT, and GGT were substantially higher in HCVinfected patients.

\section{Overall and cause-specific mortality}

Using the analytical sample as of June 30, 2014, there were $129(16.9 \%)$ deaths during 5,117 persons-year of follow-up (median follow-up 6.4 years [IQR 4.3-9.2 years]); 31 (24.6\%) deaths were observed among the $\mathrm{HCV}$-positive patients and 98 (15.4\%) deaths were observed among the HCV-negative patients. The overall mortality rate was 2.52 (95\% confidence interval [CI]: $2.12,2.99)$ per 100 person-years: $3.84(95 \%$ CI: 2.70, 5.46) in HCV-positive patients and 2.27 (95\% CI: $1.86,2.77)$ in $\mathrm{HCV}$-negative patients.

The crude HR comparing HCV-positive and HCVnegative patients was 2.00 (95\% CI: 1.32, 3.02), attenuated to $1.88(95 \% \mathrm{CI}: 1.24,2.84)$ after controlling for sex and
ALD. Figure 2 shows the survival estimates in HCV-negative and $\mathrm{HCV}$-positive patients. The conventional generalized gamma model provided a reasonable fit to the nonparametric estimates and indicated a statistically significant $34 \%$ reduction in survival times among the $\mathrm{HCV}$-positive relative to the HCV-negative patients (time ratio: 0.66; 95\% CI: 0.51, 0.86).

Overall, the main cause of death was liver-related mortality $(25.6 \%)$, followed by neoplasia $(20.2 \%)$, nonnatural (11.6\%), and cardiovascular disease (9.3\%). Figure 3 shows cause-specific mortality according to HCV status. Interestingly, liver-related death accounted for $48.4 \%$ of causespecific mortality in $\mathrm{HCV}$-positive patients and $18.4 \%$ in $\mathrm{HCV}$-negative patients. Cancer was the main cause of death in HCV-negative patients. The mortality rate due to liverrelated deaths was higher in $\mathrm{HCV}$-positive patients than in HCV-negative patients (sHR 4.25; 95\% CI: 2.07, 8.77), a difference that was significant after adjusting for sex and ALD (adjusted sHR [asHR] 3.65; 95\% CI: 1.72, 7.78; $P=0.001$ ). Figure 4 shows the cumulative incidence of liver-related death in $\mathrm{HCV}$-negative and $\mathrm{HCV}$-positive patients admitted for the treatment of alcohol dependence.

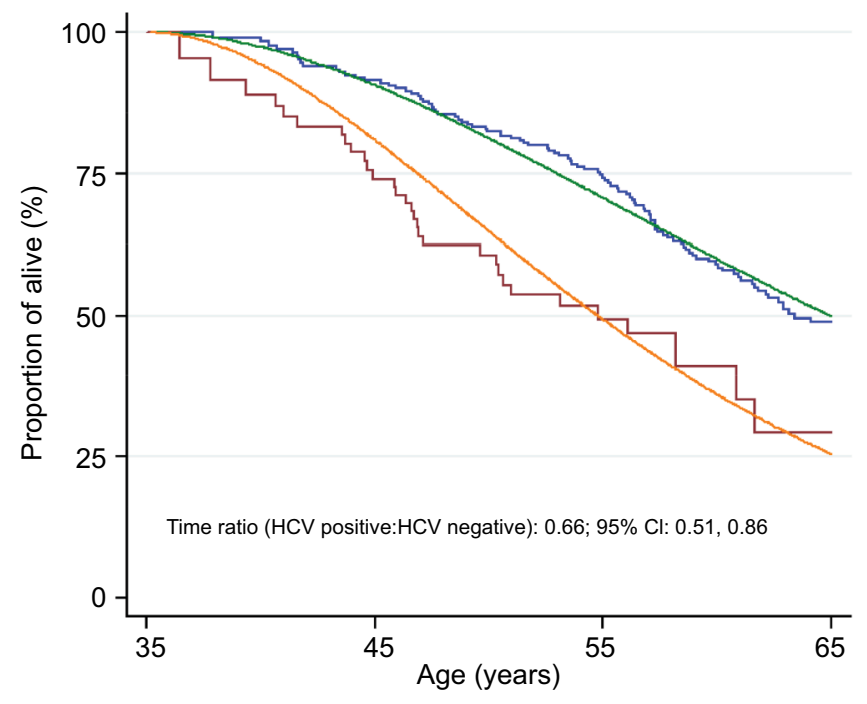

\begin{tabular}{|c|c|c|c|c|c|}
\hline & \multicolumn{2}{|c|}{$\begin{array}{r}\text { Kaplan-Meier survival curves } \\
\text { HCV negative } \\
\text { HCV positive }\end{array}$} & \multicolumn{3}{|c|}{$\begin{array}{l}\text { Generalized gamma survival curves } \\
\begin{array}{r}\text { HCV negative } \\
\text { HCV positive }\end{array}\end{array}$} \\
\hline & & \multicolumn{2}{|c|}{ Crude } & \multicolumn{2}{|c|}{ Adjusted $^{a}$} \\
\hline & Deaths & $\mathrm{HR}(95 \% \mathrm{Cl})$ & $P$-value & $\mathrm{HR}(95 \% \mathrm{Cl})$ & $P$-value \\
\hline $\mathrm{HCV}_{-}$ & 98 & 1.00 & & 1.00 & \\
\hline $\mathrm{HCV}+$ & 31 & $2.00(1.32-3.02)$ & 0.001 & $1.88(1.24-2.84)$ & 0.003 \\
\hline
\end{tabular}

Figure 2 Survival estimates in HCV-negative and HCV-positive patients with alcohol use disorders according to Kaplan-Meier and generalized gamma models. Abbreviations: $\mathrm{Cl}$, confidence interval; $\mathrm{HCV}$, hepatitis $\mathrm{C}$ virus; $\mathrm{HR}$, hazard ratio. 


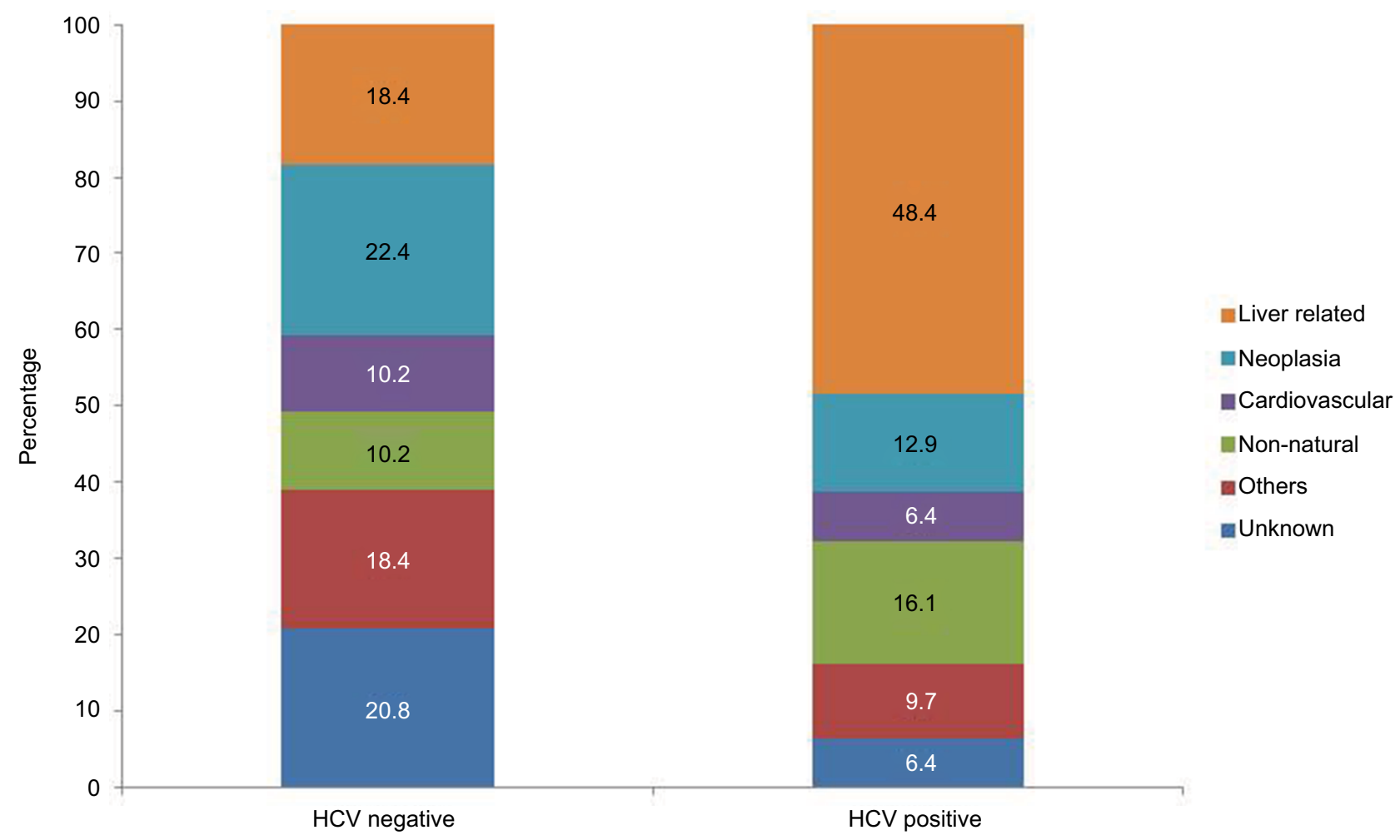

Figure 3 Cause-specific mortality in a cohort of 819 alcohol-dependent patients with and without HCV infection in metropolitan Barcelona, Spain. Abbreviation: $\mathrm{HCV}$, hepatitis $\mathrm{C}$ virus.

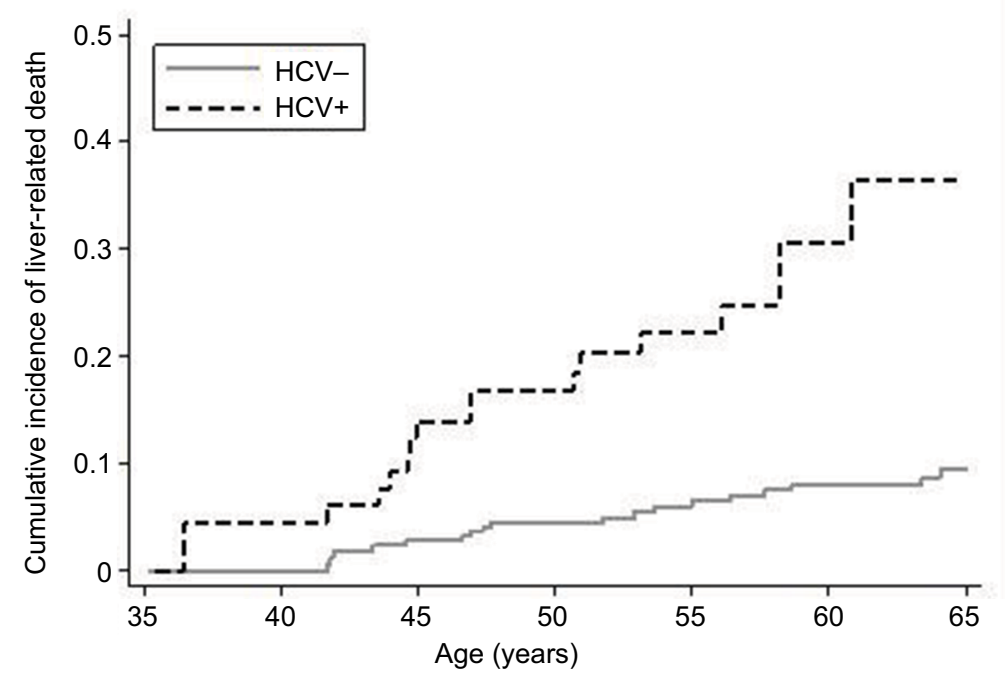

\begin{tabular}{|l|c|c|c|c|c|}
\hline & & \multicolumn{2}{|c|}{ Crude } & \multicolumn{2}{c|}{ Adjusted $^{\text {a }}$} \\
\hline & Deaths & HR $(95 \% \mathrm{Cl})$ & P-value & HR (95\% Cl) & P-value \\
\hline HCV- & 18 & 1.00 & & 1.00 & \\
HCV+ & 15 & $4.25(2.07-8.77)$ & $<0.001$ & $3.65(1.72-7.78)$ & 0.001 \\
\hline
\end{tabular}

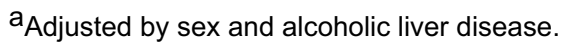

Figure 4 Cumulative incidence of liver-related death in HCV-negative and HCV-positive patients admitted to alcohol detoxification. Abbreviations: $\mathrm{Cl}$, confidence interval; $\mathrm{HCV}$, hepatitis $\mathrm{C}$ virus; $\mathrm{sHR}$, sub-distribution hazard ratio. 
Performing procedures of sensitivity analyses mentioned earlier yielded results consistent with those of the main analysis (data not shown).

\section{Discussion}

In this longitudinal study with long-term follow-up (median 6 years), HCV-positive patients had almost a two-fold increase in mortality rate with respect to patients without infection, thus indicating the negative impact of HCV infection in a population with high prevalence of infection. ${ }^{24}$ Alcohol and HCV infection are the leading causes of end-stage liver disease worldwide and the most common indications for liver transplant in the USA and Europe. ${ }^{2}$

An interesting finding from this clinical cohort is that $\mathrm{HCV}$ infection significantly reduces the survival of alcoholdependent patients with respect to those without infection. The burden of years of life lost is high if we consider that the median age of patients seeking treatment of the disorder is 44 years. To the best of our knowledge, this has not been reported previously in a series of alcohol-dependent patients.

The majority of studies analyzing the mortality of alcohol-dependent patients with HCV infection have been linked to electronic health records. ${ }^{12,25}$ In a study by Grebely et al, ${ }^{26} \mathrm{HCV}$ infection in general population had no impact on all-cause mortality but HCV infection itself was associated with liver-related death. In a diverse population of substancedependent patients admitted to detoxification, Accurso et $\mathrm{al},{ }^{27}$ also indicates that $\mathrm{HCV}$ infection is not a risk factor for all-cause mortality.

A recent study reported that up to $30 \%$ of patients with $\mathrm{HCV}$ infection may experience excessive alcohol consumption, and when both diseases occur concurrently, the liverrelated mortality is six times higher than that of HCV-negative patients with liver-related complications. ${ }^{12}$

Interestingly, in this study, the excess of liver-related mortality was explained by the impact of HCV infection; alcohol-dependent patients with HCV infection are three times more likely to die from liver-related disease than alcohol-dependent patients without $\mathrm{HCV}$ infection, which suggest that early assessment of liver damage and treatment of both alcohol dependence and HCV infection may reduce the excess of liver-related mortality in this population. In the context of a high risk of liver-related comorbidity (ie, ALD, acute alcoholic hepatitis, and cirrhosis) due to excessive alcohol consumption, HCV infection triples the risk of liver-related death. All of this reveals that it is necessary to reduce the impact of $\mathrm{HCV}$ infection in a population that does not have easy access to conventional health care. ${ }^{28}$ Changes in the treatment of $\mathrm{HCV}$ infection after the introduction of DAAs could facilitate the sustained viral response of patients, improving the survival of patients after detoxification from alcohol. Studies have shown that excessive alcohol consumption and other substance use disorders do not usually compromise adherence to HCV treatment ${ }^{29,30}$ and that persons engaged in treatment who have achieved sobriety have HCV treatment outcomes similar to those without histories of associated substance use. ${ }^{31,32}$

Despite the great impact of HCV infection in patients with excessive alcohol consumption, a recent systematic review of medical comorbidity in patients with alcohol use disorders did not include the association of HCV infection but did include heavy alcohol use with other infections, such as HIV and tuberculosis. ${ }^{33}$ Conversely, the current guidelines from the American Association for the Study of Liver Disease, the European Association for the Study of the Liver, and the World Health Organization already recommend treatment for $\mathrm{HCV}$ infection in people with substance use disorder. ${ }^{18,34-36}$

This study has several limitations. First, our analysis did not include changes in alcohol consumption over time. Abstinence from alcohol is the main goal in patients with alcohol dependence; in this sense, having information on remission and relapse of excessive alcohol use over time could better facilitate the interpretation of survival as a function of succeeding after detoxification from alcohol. Second, patients were primarily admitted to treatment because of the severity of alcohol dependence; therefore, our study did not include individuals with less severe patterns of alcohol consumption, limiting the generalization of results. Third, there may be a risk of misclassifying causes of death due to the limitations of ICD-10, which codifies death as a single cause according to a set of rules to extract maximum information. The strengths of this study are related to the well-characterized cohort that includes a large number of patient-years of observation, the analysis of causes of death and competing risks that are not usually available when using linked health records, and the sensitivity analysis suggesting that unknown causes of death have not threatened the results.

\section{Conclusion}

Alcohol abuse/dependence and HCV infection are conditions that may have clinical consequences when interacting. In summary, hepatitis $\mathrm{C}$ worsens the prognosis of liver disease and compromises the survival of alcohol-dependent patients. In this sense, treatment and care of $\mathrm{HCV}$ infection may result in better clinical outcomes in these patients. 


\section{Acknowledgments}

This study was supported by the Ministry of Economy and Competitiveness, Carlos III Health Institute (ISCIII), European fund for regional development (FEDER) (Network for Cooperative Research in Health [RETICS] RD16/0017/0003 and PI17/00174), Ministry of Health, Social Services and Equality, National Plan on Drugs (PNSD) (2014/042 and 2015/027), Fulbright Visiting Scholar Program, Ministry of Education (PRX16/00147), Spain, and Gilead Fellowship Program, Gilead Science (GLD 17/00187). The abstract of this article was presented at the International Liver Congress 2016 as an abstract presentation with interim findings. The poster's abstract was published in "Poster Abstracts" in Journal of Hepatology. 2016;64:S213-S424.

\section{Author contributions}

All authors contributed toward data analysis, drafting and revising the paper and agree to be accountable for all aspects of the work.

\section{Disclosure}

The authors report no conflicts of interest in this work.

\section{References}

1. Schuckit MA. Alcohol-use disorders. Lancet. 2009;373(9662):492-501.

2. Zakhari S. Bermuda Triangle for the liver: alcohol, obesity, and viral hepatitis. J Gastroenterol Hepatol. 2013;28:18-25.

3. Liangpunsakul S. Clinical characteristics and mortality of hospitalized alcoholic hepatitis patients in the United States. J Clin Gastroenterol. 2011;45(8):714-719.

4. Wang H, Naghavi M, Allen C, et al. Global, regional, and national life expectancy, all-cause mortality, and cause-specific mortality for 249 causes of death, 1980-2015: a systematic analysis for the Global Burden of Disease Study 2015. Lancet. 2016;388(10053): 1459-1544.

5. Mohd Hanafiah K, Groeger J, Flaxman AD, Wiersma ST. Global epidemiology of hepatitis $C$ virus infection: new estimates of age-specific antibody to HCV seroprevalence. Hepatology. 2013;57(4):1333-1342.

6. Stanaway JD, Flaxman AD, Naghavi M, et al. The global burden of viral hepatitis from 1990 to 2013: findings from the Global Burden of Disease Study 2013. Lancet. 2016;388(10049):1081-1088.

7. Taylor AL, Denniston MM, Klevens RM, McKnight-Eily LR, Jiles RB. Association of hepatitis $\mathrm{C}$ virus with alcohol use among U.S. adults: NHANES 2003-2010. Am J Prev Med. 2016;51(2):206-215.

8. Fuster D, Cheng DM, Quinn EK, et al. Chronic hepatitis C virus infection is associated with all-cause and liver-related mortality in a cohort of HIVinfected patients with alcohol problems. Addiction. 2014;109(1):62-70.

9. Kelly EM, Dodge JL, Bacchetti P, et al. Moderate alcohol use is not associated with fibrosis progression in human immunodeficiency virus/ hepatitis $\mathrm{C}$ virus-coinfected women: a prospective cohort study. Clin Infect Dis. 2017;65(12):2050-2056.

10. Muga R, Sanvisens A, Fuster D, et al. Unhealthy alcohol use, HIV infection and risk of liver fibrosis in drug users with hepatitis C. PLoS One. 2012;7(10):e46810.

11. Singal AK, Kuo Y-F, Anand BS. Hepatitis C virus infection in alcoholic hepatitis: prevalence patterns and impact on in-hospital mortality. Eur J Gastroenterol Hepatol. 2012;24(10):1178-1184.
12. Schwarzinger M, Baillot S, Yazdanpanah Y, Rehm J, Mallet V. Contribution of alcohol use disorders on the burden of chronic hepatitis $\mathrm{C}$ in France, 2008-2013: a nationwide retrospective cohort study. J Hepatol. 2017;67(3):454-461.

13. Innes HA, Hutchinson SJ, Barclay S, et al. Quantifying the fraction of cirrhosis attributable to alcohol among chronic hepatitis $\mathrm{C}$ virus patients: implications for treatment cost-effectiveness. Hepatology. 2013;57(2):451-460.

14. Szabo G, Wands JR, Eken A, et al. Alcohol and hepatitis C virus interactions in immune dysfunctions and liver damage. Alcohol Clin Exp Res. 2010;34(10):1675-1686.

15. Bukong TN, Hou W, Kodys K, Szabo G. Ethanol facilitates hepatitis C virus replication via up-regulation of GW182 and heat shock protein 90 in human hepatoma cells. Hepatology. 2013;57(1):70-80.

16. Castellano-Higuera A, González-Reimers E, Alemán-Valls MR, et al. Cytokines and lipid peroxidation in alcoholics with chronic hepatitis C virus infection. Alcohol Alcohol. 2008;43(2):137-142.

17. Vidali M, Stewart SF, Rolla R, et al. Genetic and epigenetic factors in autoimmune reactions toward cytochrome P4502E1 in alcoholic liver disease. Hepatology. 2003;37(2):410-419.

18. Clinical Practice EASL. Guidelines: management of hepatitis C virus infection. J Hepatol. 2014;60(2):392-420.

19. American Psychiatric Association. Diagnostic and Statistical Manual of Mental Disorders. 4th. (DSM IV-TR) ed. Washington, DC: Government Printing Office; 2000.

20. Lucey MR, Mathurin P, Morgan TR. Alcoholic hepatitis. NEngl JMed. 2009;360(26):2758-2769.

21. O'Shea RS, Dasarathy S, McCullough AJ. Alcoholic liver disease. Am J Gastroenterol. 2010;105(1):14-32.

22. World Health Organization. International Statistical Classification of Diseases and Health Related Problems, ICD-10. Geneva: World Health Organization; 2007. 10th revision.

23. Cox C, Chu H, Schneider MF, Muñoz A. Parametric survival analysis and taxonomy of hazard functions for the generalized gamma distribution. Stat Med. 2007;26(23):4352-4374.

24. Novo-Veleiro I, de la Calle C, Domínguez-Quibén S, Pastor I, Marcos M, Laso F-J. Prevalence of hepatitis $\mathrm{C}$ virus infection in alcoholic patients: cohort study and systematic review. Alcohol Alcohol. 2013;48(5):564-569.

25. Tsui JI, Pletcher MJ, Vittinghoff E, Seal K, Gonzales R. Hepatitis C and hospital outcomes in patients admitted with alcohol-related problems. J Hepatol. 2006;44(2):262-266.

26. Grebely J, Raffa JD, Lai C, et al. Impact of hepatitis C virus infection on all-cause and liver-related mortality in a large community-based cohort of inner city residents. J Viral Hepat. 2011;18(1):32-41.

27. Accurso AJ, Rastegar DA, Ghazarian SR, Fingerhood MI. Impact of hepatitis C status on 20-year mortality of patients with substance use disorders. Addict Sci Clin Pract. 2015;10(1):20.

28. Henry JA, Moloney C, Rivas C, Goldin RD. Increase in alcohol related deaths: is hepatitis C a factor? J Clin Pathol. 2002;55(9):704-707.

29. McCance-Katz EF, Valdiserri RO. Hepatitis C virus treatment and persons who inject drugs. Ann Intern Med. 2016;164(3):203.

30. Grebely J, Tyndall MW. Management of HCV and HIV infections among people who inject drugs. Curr Opin HIV AIDS. 2011;6(6):501-507.

31. Anand BS, Currie S, Dieperink E, et al. Alcohol use and treatment of hepatitis C virus: results of a national multicenter study. Gastroenterology. 2006;130(6):1607-1616.

32. Dimova RB, Zeremski M, Jacobson IM, Hagan H, Des Jarlais DC, Talal AH. Determinants of hepatitis $\mathrm{C}$ virus treatment completion and efficacy in drug users assessed by meta-analysis. Clin Infect Dis. 2013;56(6):806-816.

33. Rehm J, Gmel GE, Gmel G, et al. The relationship between different dimensions of alcohol use and the burden of disease-an update. Addiction. 2017;112(6):968-1001.

34. AASLD/IDSA HCV Guidance Panel. Hepatitis C guidance: AASLDIDSA recommendations for testing, managing, and treating adults infected with hepatitis C virus. Hepatology. 2015;62(3):932-954. 
35. World Health Organization. Guidelines for the Screening, Care and Treatment of Persons with Hepatitis C Infection. Geneva: World Health Organization; 2014. Available from: http://apps.who.int/iris/bitstr eam/10665/111747/1/9789241548755_eng.pdf?ua=1\&ua=1. Accessed March 20, 2018.
36. Grebely J, Robaeys G, Bruggmann P, et al. Recommendations for the management of hepatitis $\mathrm{C}$ virus infection among people who inject drugs. Int J Drug Policy. 2015;26(10):1028-1038.
Clinical Epidemiology

\section{Publish your work in this journal}

Clinical Epidemiology is an international, peer-reviewed, open access, online journal focusing on disease and drug epidemiology, identification of risk factors and screening procedures to develop optimal preventative initiatives and programs. Specific topics include: diagnosis, prognosis, treatment, screening, prevention, risk factor modification,

Submit your manuscript here: https://www.dovepress.com/clinical-epidemiology-journal

\section{Dovepress}

systematic reviews, risk and safety of medical interventions, epidemiology and biostatistical methods, and evaluation of guidelines, translational medicine, health policies and economic evaluations. The manuscript management system is completely online and includes a very quick and fair peer-review system, which is all easy to use. 